\title{
From Things to Thinking: Cognitive Archaeology
}

Adrian Currie \& Anton Killin

Penultimate version, forthcoming in Mind \& Language

\section{Acknowledgements}

This paper was read by Exeter University's Culture \& Cognition group, who provided invaluable feedback. Alexandra Ion, Kim Sterelny, Sarah Jackson and Greg Currie all provided useful comments on drafts. Adrian's research was supported by a grant by the World Templeton Charity Foundation.

\begin{abstract}
Cognitive archaeologists infer from material remains to the cognitive features of past societies. We characterize cognitive archaeology in terms of trace-based reasoning, that is, cognitive archaeology involves inferences drawing upon background theory linking objects from the archaeological record to cognitive (including psychological, symbolic, and ideological) features. We analyse such practices, examining work on cognitive evolution, language, and musicality. We argue that the central epistemic challenge for cognitive archaeology is often not a paucity of material remains, but insufficient constraint from cognitive theories. However, we also argue that the success of cognitive archaeology doesn't necessarily require well-developed cognitive theories: success might instead lead to them.
\end{abstract}

\section{Introduction}

Human cognition and things are intimately linked: we build tools and manipulate our environment; we innovate, experiment, and probe. Regardless of cognition's exact nature and its precise relationship with materiality, this suggests that much can be gleaned about mental and 
cultural lives from material objects. This thought underwrites cognitive archaeology: using the material remains of past cultures as inferential windows to the development of human thought, past inner lives and social practices.

Cognitive archaeology is crucial for telling the story of human culture and minds; for understanding who we are, where we came from, and what—if anything—makes our species special. But what conceptual and epistemic constraints are there, and what exactly does cognitive archaeology have to offer? In this paper we'll provide a novel characterisation of cognitive archaeology and draw some conclusions about the epistemic possibilities and problems such an approach faces. Instead of directly engaging with debate within archaeological theory, our aim is to defend a conception of cognitive archaeology relevant to those generally interested in the nature of language, cognition and their evolution.

We begin in section 2 with a sketch of cognitive archaeology. Section 3 draws on case studies which link lithic technologies to the evolution of mind and language, Section 4 draws a set of philosophical lessons from those discussions, and Section 5 offers concluding remarks.

\section{What is Cognitive Archaeology?}

'Cognitive archaeology' refers to a diverse research program. To see why, it is useful to situate ourselves in archaeology's history. As Alison Wylie tells it, archaeology is marked by 'crisis debates': a more-or-less regular oscillation between two philosophical extremes (see Wylie 1985; Chapman and Wylie 2016; also Abramiuk 2012, chapter 1). On one extreme, archaeologists commit to often naïve conceptions of scientific objectivity; on another, they reject objectivity as a possible or desirable goal. Cognitive archaeology emerged as a reaction to the 'New Archaeology' of the 1960 s and '70s—often called processualism—which tended towards the first extreme. The development of radiometric dating methods provided archaeologists with the means to date events in human prehistory in testable (and thus scientifically-credible) ways 
(although for limitations see Chapman and Wylie 2016). Inspired by the prospects unlocked by this strategy, processualists aimed to develop similarly rigorous grounds for inferring from material remains to ancient human life-ways. Although proponents of processualism took archaeology's task to involve understanding human cultures (e.g., Binford 1972), their conservative epistemological stance meant that processualists often restricted their explanatory scope to human subsistence and settlement. Although processualists presumed a strong link between subsistence behaviour — the daily grind necessary for eking out a living —and demographic patterns of settlement, for them the material record shed little if any light on matters of cognition.

The rationale behind focusing on subsistence and ecology is that physical environments and survival place tight constraints on human behaviour, and so licence stable inferences. The further one strays into the contingently human -into the cultural, mythic and political spheres - the weaker the inferences (Hawkes 1954). Or so the thought goes. Although founding processualist archaeologists such as Christopher Hawkes didn't rule out the cultural and the cognitive from archaeology's purview, they did think that the further archaeology shifts from subsistence, and from textual history, the more problematic the inferences become. In practice this led to a narrow focus on those safer inferences. And thus, it seemed, a strict requirement for epistemic responsibility denied archaeologists access to much of the cognitive. ${ }^{1}$

Archaeologists pushed back against subsistence-settlement archaeology, and the diversity within cognitive archaeology arises from the diversity of reactions to that older practice. Roughly speaking, one group extended processualism by affirming scientific routes into our cognitive past, typically by utilizing a wider theoretical toolkit (Renfrew 1993; Peebles 1993). Another set rejected processualism altogether (Hodder 1993; Bender 1993). Such 'post-processualists' took a

\footnotetext{
${ }^{1}$ Lewis Binford, for one, argued that the social and ideational could in principle be glimpsed from subsistence, given the tight coupling between subsistence and social organization/ideology: this in part opened up the possibility of a processualist cognitive archaeology.
} 
hermeneutic ('interpretative') approach and emphasized self-conscious reflexivity on the part of archaeologists themselves: they stressed that their own cognition was deeply biased, and that archaeology necessitates a dialogue between the present and the past. Today, archaeology is deeply disunified theoretically (Ribeiro 2018) and cognitive archaeology is just one thread among many. Our focus will be on the processualist tradition, but the post-processualist emphasis on the reflexivity of archaeological inquiry matters for our concluding discussion; moreover, we focus on the nature of the inferences drawn — the reasoning practices of cognitive archaeologists—rather than the more metaphysical contexts in which archaeological theory is typically debated.

And so, cognitive archaeology arises from an insistence that the material remains of the archaeological record can provide stable, warranted access to the minds and cultures of the peoples of the deep past. It is, at base, a reaction to a perceived conservative focus on ecology and subsistence. Within these broad strokes, a variety of definitions and strategies have been suggested. We'll start with a brief example, before drawing on some philosophical machinery to provide a definition.

\subsection{Material Music}

The remains of musical instruments can underwrite powerful inferences to the cognition of those who built and used them.

In 2008, one of the oldest flutes (pipes) currently known was discovered in Hohle Fels in southwestern Germany (Conard et al. 2009). Constructed from a vulture's wing bone (a typical raw material for flutes; see Morley 2013), it is dated to approximately $40 \mathrm{kya}^{2}$ At nearly $22 \mathrm{~cm}$ long and sporting five fingerholes, the object appears to be virtually complete. The bone was scraped smooth, finger-holes were created by etching concave depressions and then piercing

\footnotetext{
${ }^{2}$ We use 'kya' to denote 'thousand years ago' and 'mya' for 'million years ago'.
} 
them, and the proximal end of the bone was adjusted to better function as a mouth-hole. Cut marks near the finger holes suggest they were intentionally measured and placed, although the underlying reasons are unknown (perhaps physical practicality, pitch convention, or pedagogy).

Archaeologists have claimed that such flutes are "fully developed musical instruments" (Conard and Malina 2008, p. 14) and that they must be "several conceptual stages removed from the earliest origins... of instrumental musical expression" (d'Errico et al. 2003, p. 46), underscoring the technological and musical competences of ancient humans. Thus music must have mattered to Upper Palaeolithic humans: why else dedicate such time, energy and resources to it?

Inference from flutes to the importance of music in the societies that built them illustrates a common mode in cognitive archaeology: minimal-capacity inference. Minimal-capacity inferences identify plausible pre-conditions for the production of some object, and then infer from the objects to those pre-conditions. That is, the minimal capacities allegedly required for the production of the object ground the inference. Sophisticated instruments don't arise wholecloth, so these flutes signal a developed technological and cultural tradition, and thus also the cognitive wherewithal required for such traditions. Similarly, you don't put highly skilled labour into musical instruments unless music matters, so caring about music is a minimal condition for the production of complex musical instruments.

Ancient flute-makers didn't restrict themselves to bone, but utilized other materials as well. The oldest known mammoth ivory flute is near-contemporary with the oldest known bone flutes, and ivory flutes bespeak yet more sophisticated production methods. The wing bones of birds make for ideal flute-material: they are naturally hollow, of an appropriate size, easy to craft, and combine being light-weight with sturdiness. Ivory is tough to work, the wrong size, heavy, and dense. So, to make a flute from ivory, Morley tells us: 
... a section of ivory must be sawn to the correct length, it must then be sawn in half along its length, the core lamellae (layers) must be removed, and then the two halves of the flute must be refitted and bound together with a bonding substance which must create an airtight seal in order for the pipe to produce a sound. (Morley, 2013, p. 50)

A nontrivial procedure! Yet replica experiments suggest ivory flutes were at best equivalent, or even inferior, to bone flutes (Conard and Malina 2008). Playing a flute introduces moisture, softening the adhesive holding the halves of the ivory flute together. After half an hour of playing, re-gluing—or at least touching up—is needed to keep the flute airtight. Ivory flutes were thus costly to create and maintain. Given these costs it's not a stretch to think that ivory flutes indicated social status or significance (for example, they may have had a special ritual function). Such differentiation in flutes, particularly between the more practical bone flutes and difficult-toconstruct ivory ones, potentially then signals increasing social differentiation (and the socialhierarchical thinking that would accompany it) in Upper Palaeolithic human societies (Killin 2018).

This inference is not based on minimal capacity, but is what we'll call a causal-association inference. While minimal-capacity inferences identify preconditions for some property and infer from the property to those preconditions, causal-association inferences draw on multiple lines of evidence to build a case for a (non-necessary) association between a material trace and a feature of past societies. For instance, Kuhn (2014) argues that cumulative shifts in Late Pleistocene human adornment technologies_-from the use of ochre and pigment, to beads, to more complex ornaments and grave goods_-reflects changing social dynamics and increasing social complexity, and Killin (2018) fits musical artefacts into this general framework. Evidence relating costly items with little functional purpose to social differentiation (e.g., by examining differences in material culture between more and less differentiated societies) adds to the case for taking the existence of such items as signals of social structure. Such inferences may be purely associative, based on a robust correlation between two properties, or they can involve causal modelling. Causal-association and minimal-capacity inferences are distinguished by, first, their 
differing logic: with minimal-capacity inferences, one infers from an alleged necessity, while causal-association inferences are inductive. Second, their differing epistemic support: causalassociation inferences typically rely on multiple lines of evidence to build the association.

\subsection{Cognitive archaeology characterized}

As we've seen, cognitive archaeologists are in the business of using material remains (ochre, beads, bone and ivory flutes) to make claims about the mental and cultural ${ }^{3}$ lives of past humans (societies were increasingly socially differentiated in the Late Pleistocene). However, human behaviour is cultural, technological, cognitive behaviour, so what might delineate cognitive archaeology from other research programs? We think cognitive archaeology is best understood as involving a kind of trace-based reasoning.

Trace-based reasoning in general takes some contemporary phenomena—some physical trace: a modified bone, say —and then, via understanding the processes by which such remains form (via 'middle-range', or 'midrange' theory), infers claims about past states of affairs (see Currie 2018, chapter 3; Kosso 2001; Jeffares 2008). ${ }^{4}$ In the trace-based reasoning of cognitive archaeology, the traces are the material remains of past human/hominin activity, the claims are about cognitive/cultural features, and the midrange theories are those which link those features with material remains. The midrange theory at hand, then, concerns the expression of thought, psychology, sociality, ideology, and myth in material remains. Such are the ingredients which take us from things to thinking.

\footnotetext{
${ }^{3}$ Archaeologists often use 'cultural' in a very broad sense, to include subsistence activities, and so forth. We here use it in a narrower sense to mean complex, contingent social activities such as institutional or religious structures.

4 'Middle-range' theory is Lewis Binford's term, and it is intended that the regularities involved are not 'lawlike' but rather occupy a 'middle range' between laws and particulars.
} 
Our account aims to strike a balance between being too narrow and too permissive. ${ }^{5}$

On the too-broad side, Flannery and Marcus (1993) define cognitive archaeology as "the study of all those aspects of ancient culture that are the product of the human mind"; they include a long list of examples but specifically "make no mention of such common subsistencesettlement behaviours as hunting, fishing, farming, plant collecting, tool-making and so on" (p. 261). Such definitions are in explicit opposition to earlier processualist approaches. It is unclear whether such a broad definition is particularly helpful. As Colin Renfrew put it: "Nearly every human enterprise has its cognitive aspect, and every thought which finds expression in the archaeological record must have been accompanied by an action leaving some material trace" (1993, p. 248). Simply defining cognitive archaeology as not being subsistence archaeology both misses the connections between subsistence and cognition, and is uninformative, failing as it does to identify what is distinctive of the practices of cognitive archaeologists.

Other definitions are narrower. Thomas Wynn (2017), for instance, specifically links psychological theories to cognitive archaeology. His proposal, in our parlance, would claim that only inferences using midrange theories from psychology would count. We think there are reasons to reject accounts like Wynn's. First, the need for midrange theories to be explicitly psychological holds cognitive archaeology hostage to those theories. Wynn himself points out that a commitment to the theories of Piaget undermined early approaches to cognitive archaeology. As Piaget's theoretical work became questioned, so too were the archaeological inferences made on the basis of that work. ${ }^{6}$ On such accounts, the epistemic power of cognitive archaeology is held hostage to the fate of the psychological theories at hand. Such worries often

\footnotetext{
${ }^{5}$ Notice that our characterization is silent on matters of disciplinary background or membership, institutionally defined. As we see it, cognitive archaeology today comprises a diverse research cluster of archaeologists, psychologists and cognitive scientists, philosophers, and cultural theorists. This disciplinary diversity is reflected in the case studies discussed in Section 3.

${ }^{6}$ Another example is Christopher Peeble's appeal to 'capital EP' Evolutionary Psychology, which we take to have been seriously challenged (e.g., Downes 2010).
} 
underwrite demands for new theoretical frameworks and methods which can "make proper use of theory from the behavioral and neurosciences to support inferences from and about the archaeological record" (Barnard et al. 2017, p. 46). Second, we think theories need not be explicitly psychological to take us from material remains to culture and cognition: consider Renfrew's use of symbolic theory (Renfrew 2012), Kuhn's use of biological signalling theory (Kuhn 2014), and the more local, bottom-up midrange theories we'll highlight through the case studies in the next section. Third and finally, such accounts potentially privilege psychological (or neuroscientific) theory over the more local theories and hypotheses which we think are often doing the heavy lifting in archaeological inferences in practice. Consider, for instance, the reasoning behind the inference from bone and ivory flutes to the significance of music we have just seen. In that context, general theories of human cognition (much less neuroscientific ones) do significantly less work than ideas about the capacities of the physical structures themselves, and what goes into constructing them. We don't think a preference for some kind of theory over another should be baked into our conception of cognitive archaeology.

So, cognitive archaeologists infer from material traces to the cultural and cognitive past using midrange theory connecting them. On our account, the potential of cognitive archaeology is constrained by the availability of material remains, and the tightness of the links between material remains and the cognitive features of interest. In the next section, we discuss case studies linking lithic technology to the evolution of mind and language. In section four, we argue that it is not a lack of material remains, but how well understood and constraining our midrange theory is, which presents the biggest challenge to cognitive archaeology.

\section{Lithics, Mind, and Language}

Constructing complex musical instruments from bird bones and mammoth ivory requires fancy cognitive capacities: forward planning (and thus 'mental time-travel'), good working memory, 
focus and impulse control, impressive manual dexterity, and task specialization. But it is hardly controversial that humans a measly 40,000 years ago were capable of all this. Humans have been human (i.e., anatomically modern) for at least 200,000 years; perhaps 300,000. What's controversial is locating these capacities significantly earlier. Some argue that the Acheulean lithic industry (see Table 1)—beginning over 1.5 mya and lasting over a million years—gives us reason to push back hominin possession of these traits to significantly earlier dates. This involves a minimal-capacity inference: from the presence of material remains (Acheulean stone tools) to cognitive properties via midrange theories which, for instance, take mental time-travel to be necessary for the complex tasks involved in generating the object.

As is appropriate for a minimal-capacity inference, the debate turns on the cognitive capacities required for the production of the tools. As far as the Oldowan industry (see Table 1) is concerned (and even earlier-see Balter 2015; Harmand and Lewis et al. 2015), stone tool production was plausibly perpetuated by simple imitation and individual experience. Gary Tomlinson (2015) argues that little more is required for Acheulean stone tool production. Even as far into the Acheulean phase as 1 mya, Tomlinson sees stone tools as the result of fully embodied, unplanned, opportunistically-enacted actions, transmitted socially via straightforward mimetic copying and trial-and-error learning. Tomlinson does not deny Acheulean knappers complex sociality, but envisions their minds as being largely great-ape-like. Thus the outcomes of the production sequence (bilateral symmetry, tear-drop shapes, etc.) were neither pre-planned nor intended, on his view, but were by-products of the embodied "standardized sequences of gestures.... [T]hinking of the hominin mind dictating symmetries has it backwards; it is the bodystone interaction from which symmetries (and perhaps even the mind) emerge" (Tomlinson 2015, pp. 67-68). Note that Tomlinson's argument turns on the mental capacities required for producing the traces in question: he aims to undermine the minimal-capacity inference from lithic remains to an advancement in cognitive competences. 


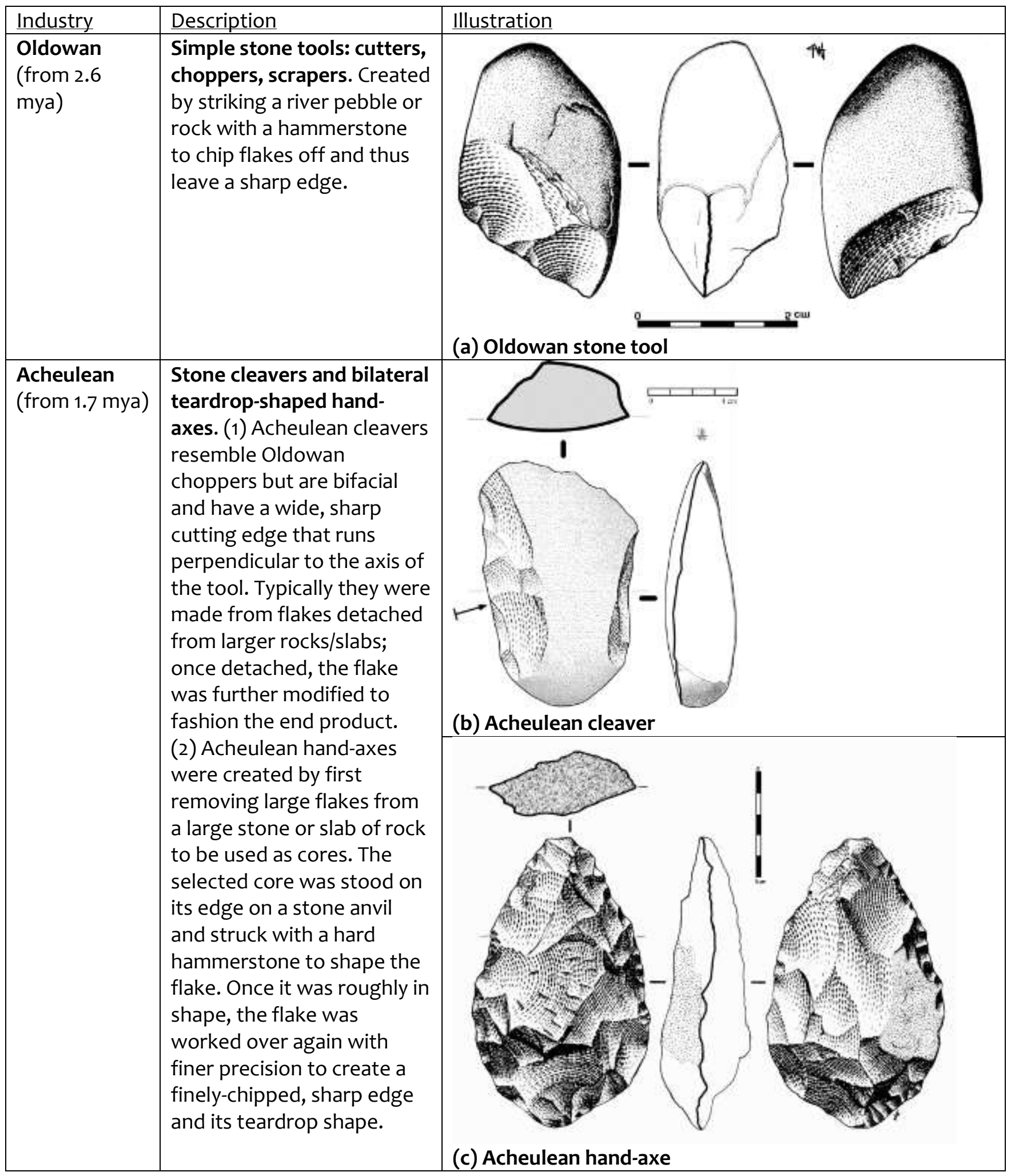

TABLE 1 Descriptions and illustrations of stone tools from the Oldowan and Acheulean industries. Images (a) and (c) have been released into the public domain; image (b) is reproducible under the terms of the Creative Commons Attribution-Share Alike 2.5 Generic License. Attribution (a-c): José-Manuel Benito Álvarez. Sources= (a) https://en.wikipedia.org/wiki/Stone_tool\#/media/

File:Chopping_tool.gif; (b) https://en.wikipedia.org/wiki/Cleaver_(tool)\#/media/File:Hendidor.png; (c) https://en.wikipedia.org/wiki/Stone_tool\#/media/File:Hand_axe_spanish.gif. Accessed 16 January 2019 
Killin (2016, 2017a), among others, is sceptical of Tomlinson's proposal. The symmetry exhibited in Acheulean lithics, for example, is arguably too technically demanding to be the inevitable outcome of an enacted unplanned operational chain of gestures. As Peter Hiscock puts it:

[Knapping] is intrinsically a complex process that requires competency at a number of levels simultaneously: bio-mechanical capacity to strike accurately and forcefully; the capacity to anticipate and identify emerging problems in the specimen morphology and to apply an effective action from a repertoire of potential responses; the capacity to plan ahead, which involves mental projections of both future actions and predicted outcomes. (Hiscock 2014, p. 34)

Hiscock (2014) argues knapping is a dangerously unforgiving pastime. You must know what you're doing to avoid a shard of rock in the eye, or disfiguring your hand. You couldn't unwittingly enact an embodied sequence of unintentional gestures without risking severe injury. And complex production methods comprising hierarchically organized stages are unlikely to be the inevitable outcome of embodied, unplanned patterns of physical actions. ${ }^{7}$ Consider the constraints of working with the large slabs of rock $(\sim 65 \mathrm{~kg})$ from Isampur Quarry, from which flakes were struck to be used as cores for reduction:

Experimental evidence shows that stabilizing the core could be achieved in one of two ways: either one person could lift the core while another put dirt underneath to cushion it and prop it up, or the second person could hold the core directly while the first person strikes it.... Either way, producing large flake blanks from these giant cores was apparently a two-person job. (Shipton and Nielsen 2015, p. 339)

So Killin (2016) supposes, contra Tomlinson, that Acheulean tool production is not unplanned/unintended work: Acheulean tools are instead a signal of salient cognitive capacities (see also Jeffares 2010; Shipton 2013; Hiscock 2014). These capacities include the following:

\footnotetext{
${ }^{7}$ See Shipton and Nielsen (2015) for a discussion of the method of production of stone cleavers.
} 
(1) shared intentionality, which involves recognising another's intention, and thus at least basic theory of mind;

(2) episodic memory, making intentional repetition of past successful knapping gestures possible;

(3) forward planning and thus at least basic mental time-travel (during the Acheulean's early phase, tools or the raw materials for tools were transported from their sources for up to $13 \mathrm{~km}$, increasing to $100 \mathrm{~km}$ by the Acheulean's later phase-see Marwick 2003; Petraglia et al. 2005);

(4) mental models/templates, involving a (presumably crude at first) representation of the end product (of course, there is much variation with respect to shape and symmetry in the record-McNabb et al. 2004; Petraglia and Shipton 2008);

(5) impulse control and attentive focus, since production methods (from sourcing the raw material, testing it for suitability, to knapping the finished item via several stages) require some level of commitment to the task in the face of moment-to-moment distraction; many Acheulean tools were knapped for use in the 'elsewhere and elsewhen' and their benefits were not found in the here-and-now as knappers produced them (Jeffares 2010);

(6) greater executive motor control of the hand and arm, as manual dexterity and tools co-evolve (Marzke 2013);

(7) greater communication skills: gestural communication—pointing, miming, etc., alongside vocalisations for emphasis and to command attention-would have proved very useful in coordinating joint activities and in transmitting knapping skills (Sterelny 2012); 
(8) greater intentional listening, as sound provides an effective means of diagnosis for the suitability of raw material (Killin 2017a; Morley 2013).

If something like this is right, then basic forward planning, more-than-rudimentary theory of mind, explicit teaching, and simple mental models were part of the Acheulean cognitive repertoire. ${ }^{8}$ This thought becomes more compelling when linked to other lines of evidence that also point to advances in cognitive evolution, such as encephalization increases (Antón and Snodgrass 2012; Antón et al. 2014), coordinated big-game hunting (Bunn and Pickering 2010a, 2010b; Pickering and Bunn 2012; Stiner 2013) and, although controversial, early fire use (GorenInbar er at. 2004; Wrangham 2009; Attwell et al. 2015; Gowlett 2016).

Debates such as that between Killin and Tomlinson are not over psychological or cognitive theories per se, but concern the cognitive and social capacities required to produce certain kinds of objects. Killin thinks greater cognitive and social wherewithal is necessary to explain what is found in the Acheulean record than Tomlinson does, and thus at least some of the disagreement between the two theorists is over which minimal-capacity inferences are applicable. As we'll expand on below, we think such disputes are common in cognitive archaeology and as they do not turn on any specific psychological theory, these undermine characterizations of cognitive archaeology that require explicit psychological theories (cf. Wynn 2017).

Theory plays a more explicit role in debates about the origins of language. According to many associated with Chomskyan minimalism, language evolved catastrophically (see e.g. Berwick and Chomsky 2015; Chomsky 2007). Chomskyans are saltationists, positing the abrupt onset of "Merge", a single grammatical operation which allowed lexical items to be recursively combined. Before Merge, only very simple communication was possible, involving only the external

${ }^{8}$ Greg Currie (ms) argues that Acheulean lithics also evinces an aesthetic sensibility: that ancient hominins found certain objects aesthetically pleasing; Killin (2018) is sympathetic to this idea, though loosens the concept at stake to the 'proto-aesthetic'. 
expression of basic internal concepts. Afterwards, the emergence of fully-fledged language was possible. ${ }^{9}$ In Chomsky's words, "a rewiring of the brain took place in some individual, call him Prometheus, yielding the operation of unbounded Merge" (2010, p. 59); "Perhaps it was an automatic consequence of absolute brain size... or perhaps some minor chance mutation" (2007, p. 18). According to Chomskyans, public language appeared less than 100,000 years ago and is evolutionarily continuous only with an internal/private language-of-thought ('i-language') and not with conspecific communication (external, 'e-language').

Ian Tattersall (2017), a leading Chomskyan archaeologist, associates language with symbolic behaviour which he argues is not evident in the archaeological record until around $100 \mathrm{kya}$. This causal-association inference relates a category of material features to language capacities in order to provide a theoretical basis for investigating anticipated differences in the archaeological record before and after language, in this case, the absence or presence of symbolism. For Tattersall, symbolic material culture is language's 'smoking gun': he argues that traces of symbolism are absent before 100 kya and thus that language's presence before that time is unlikely.

Of course, one does not need to accept the Chomskyan emphasis on internal language in order to conceive of language as a late-evolving phenomenon. Davidson and Noble (1989) adopted a nonrepresentational, ecological-psychological theory of cognition (Gibson 1986), according to which organisms respond to 'perceived energy fluxes' (e.g., acoustic or electromagnetic) in their environment. On Davidson and Noble's picture, mimicry was a necessary prerequisite for the emergence of depiction, which in turn was a necessary prerequisite for the evolution of language. And since depiction crops up late in the archaeological record, Davidson and Noble argue that so must have language.

\footnotetext{
${ }^{9}$ For an extended critique of Chomskyan language evolution, see Planer (2017c).
} 
Gradualists, on the other hand, typically see language as evolving incrementally over a long period of time. On such views, language is evolutionarily continuous with earlier traits: either the largely gestural communication systems of great apes (Hewes 1973; Tomasello 2008; Sterelny 2012; Corballis 2017; Killin 2017b), or the vocalisations (possibly song-like, possibly word-like) of our deep-past ancestors (e.g., Darwin 1871; Mithen 2005; Fitch 2010). Gradualists often hunt for precursor systems to language—-sometimes called 'protolanguages'—communication traditions that have some, but not all, of the distinctive features of modern and ethnographically-known languages. Here we focus on Ronald Planer's (2017a, 2017b) account, which links language to Acheulean lithics.

Planer argues that Early Pleistocene hominins had protolanguage on the basis of Acheulean material remains, particularly tools. First, he outlines a "package of cognitive abilities" that are "sufficient, given appropriate socio-ecological conditions, for the emergence and continued existence of language" (Planer 2017b, p. 212). Second, he provides archaeological evidence suggestive of the presence of these abilities in ancient hominins. Third, he offers an argument to the effect that ancient hominins would have been much advantaged by—and would have genuine uses for-such a protolanguage.

Here, Planer makes a causal-association inference. Notice that supporting such inferences often involves a two-way dialogue between theory and evidence: one doesn't start with an $a$ priori theory and then fit the evidence to it, rather the two evolve together. Planer does not intend to 'prove' the existence of an Acheulean protolanguage, instead providing a 'proof of concept': an incrementalist-friendly route that hominin language evolution could have taken.

Planer's cognitive package includes (1) the cognitive competences of extant primates plus (2) informational theory of mind, the "ability to mentally represent other agents as possessing certain information-carrying states as well as states that specify an environmental condition that the agent is motivated to bring about" (p. 212), (3) mental-model construction, the ability to 
construct mental representations/templates of situations, and (4) imitation of interpersonal acts, the ability to mimic the actions of other individuals. (For why he think this cognitive package suffices for protolanguage see Planer 2017a.)

To illustrate Planer's reasoning, we'll focus on informational theory of mind, which Planer (2017b) links to instructed learning. He suggests the expertly-knapped Acheulean tools depended on explicit teaching, not merely on individual observation. He notes that modern humans require extensive training and rehearsal to develop comparable knapping skills (Stout 2002), and that Acheulean patterns of raw material selection (see Shipton et al. 2009) suggest demonstration and error correction. For Planer, instructed learning "constitutes evidence for an increased understanding of others as intentional agents relative to that which was present in our last common ancestor with chimpanzees" (p. 215), something tantamount to an informational theory of mind. So, he infers from Acheulean tools, to theory of mind (inter alia), to the existence of protolanguage.

Both incrementalists and saltationists about language offer 'ingredients' required for its emergence, and attempt to link these to material remains in evidencing their hypotheses. The interaction between theory (the ingredients) and the remains is not one-way: features of the record are used to critique and develop theories of language. And intimate examination of the materials is often a flash-point of debate. Thus, cognitive archaeology is a means for bringing the theoretical and empirical into profound, two-directional contact.

As we've seen, a characteristic form of reasoning in cognitive archaeology involves minimalcompetence inferences. These take kinds of cognitive capabilities or cultural features to be necessary for the successful production, or motivation to produce, kinds of material goods. In such inferences midrange theory links material remains to past capacities via the claim that those capacities are a necessary condition for the generation of those goods. As a result, debate in cognitive archaeology frequently turns on what is theoretically required to produce items and 
patterns in the archaeological record. That is, disputes often turn on midrange theory. Note again that discussions don't always turn on 'capital T' Theories from psychology per se. One needn't commit to, say, cognitivism or non-cognitivism to debate whether certain activities require forward planning, although considering whether this is the case might inform us about such theories. Moreover, cognitive archaeologists rarely if ever have direct evidence of the mechanisms underlying the cognitive capacities at stake in some debate. But this needn't discourage progress: often one need only commit to theories of the 'performance specs' of ancient minds (as Kim Sterelny has put it to us) —what operations ancient minds were able to perform—not to theories of how those minds are computationally or neurally structured to meet those specifications.

As we've seen, causal-association inferences are a further mode of inference in cognitive archaeology. Here, multiple lines of evidence connect some feature of a practice to its material remains. Planer constructs an associative case, drawing on a broad array of evidence, to argue for language's incremental emergence. We can connect the sophistication of Acheulean tools with other hominin features such as signals of hunting, brain-size increase, and so forth. Instead of a necessary connection or precondition as in minimal-capacity inferences, we draw on multiple lines of evidence to build an empirical tool provisioning access to the past.

In the next section we draw on these points to argue that (1) the main challenge for cognitive archaeology involves midrange theory and yet (2) a successful cognitive archaeology need not commit to any particular psychological or cognitive theory, and further (3) cognitive archaeology not only provides an important line of evidence for reconstructing the past, it also necessitates critiques and developments of theories of human cognition.

\section{Epistemic Challenges \& Value}


Here we make some philosophical points about the value of and challenges faced by cognitive archaeology. We'll start by considering the role of theories.

Distinguish between two roles theories of cognition might play in cognitive archaeology. First, they can be midrange theories: that is, provide licence to take material remains as evidence of past cognition. Second, cognitive theories can be tested against the historical record that archaeology reveals. Insofar as different theories make different claims about the timing or ordering, or dependencies between, various cognitive capacities, these can be potentially tested against the historical record. Our claim that grander (capital ' $T$ ') cognitive or psychological theories are not necessary for much cognitive archaeology is more precisely the claim that they rarely play the role of midrange theory. Most of the inferences cognitive archaeologists make are compatible with multiple general theories of cognition, and only once the historical sequence of events emerges might such theories be put to the test. And a good thing too. If a theory has been used to interpret the record (that is, acting as midrange theory), then using the resulting interpretation to support that theory could be problematic (what Bell 2015 calls 'xeroxing'). This suggests that a primary value of cognitive archaeology is providing new empirical routes into testing cognitive theories. Below, we'll suggest another. But before that, let's consider three epistemic challenges to cognitive archaeology: whether intentions or culture are the proper target of such inferences at all, whether there are sufficient material remains, and whether midrange theory is sufficiently constraining.

We might worry about the possibility of inferring from material remains to intentions or cognitive states in the first place. Because these states are internal mental states, inferences from their material products are just too indirect and underdetermined to be justified, or perhaps we make a mistake by drawing apart intentions from materiality in the first place. We're not moved by this. Some archaeologists, in effect, collapse cognition with its material remains (a variety of behaviourism), or with past features more intimately connected to remains: for 
example, "[the] symbolic and cognitive are largely equivalent" (Renfrew 1993, p. 249). If Renfrew's right, then arguably intentions are not private, and by accessing interpersonal symbolic meaning we access intention. Outside cognitive archaeology, contemporary archaeologists often cast this kind of approach in explicitly metaphysical terms, claiming that splitting intentions from behaviour (or material culture) is an example of a problematic ontological dualism (see, for instance, Harris 2018). But we needn't (and, we think, shouldn't) go this far. First, any inference to the past involves fallible induction. Underdetermination is common in historical science (Turner 2005), and no doubt rife whether we're interested in subsistence or spirit. Second, we shouldn't prejudge which aspects of the past are accessible and which aren't: determining epistemic access requires putting in the empirical hard yards, and whether some past fact is accessible or not depends upon fine-grained features of the context at hand (Currie 2018). As such, simply writing off cognitive, intentional and mental capacities as being generally inaccessible is unjustified. Third, even if cognitive archaeology is the practice of shifting from things to thinking, such inferences shouldn't be considered in epistemic isolation. Marcus and Flannery (1994) preferred to name their practice holistic rather than cognitive archaeology, emphasizing the need to incorporate many lines of evidence from multiple perspectives to get to the cultural and cognitive (a common theme: Peebles 1993; Ion 2017; Wylie 2011; Stiner and Kuhn 2016; Flannery and Marcus 1993; Currie 2016; Currie and Killin 2016; Abramiuk 2012). Although simple models connecting particular material remains to cognitive faculties are the bedrock of cognitive archaeology, making convincing inferences about the cultures and minds of past people usually does require integration with many lines of evidence. But that's hardly surprising: historical scientists are 'methodological omnivores' (Currie 2015, 2018).

A second worry (and we think the most common) points to a lack of material remains. Consider Richard Lewontin on cognitive evolution: 
... the best lesson our readers can learn is to give up the childish notion that everything that is interesting about nature can be understood. History, and evolution is a form of history, simply does not leave sufficient traces... It might be interesting to know how cognition (whatever that is) arose and spread and changed, but we cannot know. Tough luck (Lewontin 1998, p. 130).

Flannery and Marcus (1993) also worry that without a "sufficiently rich" body of supporting data “cognitive archaeology becomes little more than speculation, a kind of bungee jump into the land of fantasy" (p. 261). Although more optimistic than Lewontin, Flannery and Marcus agree that downstream remains are a major constraint on cognitive archaeology. On such views, then, the main challenge for cognitive archaeology is finding traces of our cognitive pasts. We think this is a mistake: in principle, there are bountiful remains of past cultural lifeways.

While it is true that many interesting things about cognition and its evolution may never be known, it is not a lack of material remains that challenges cognitive archaeology, it is a lack of well-grounded theories which connect those remains to their idiosyncratic cultural and cognitive origins. Despite issues of preservation, finding remains should not be problematic because human activities are cultural, cognitive activities: we occupy highly social, scaffolded epistemic niches (Sterelny 2003). Human action is intentional action: subsistence is not decoupled from the cultural or cognitive. Given this, any human remain will in principle carry with it rich information about the local and idiosyncratic culture and cognition underwriting it. The trick is to decode that information.

This response shouldn't be taken too far: evidence of the past is sometimes truly impoverished. (The Denisovans, an ancient hominin species, for instance, are known only from a few bone fragments. ${ }^{10}$ ) Traces erode and decay, and without material culture, cognitive archaeology cannot get off the ground. So new evidence is always desirable, obviously. It can

\footnotetext{
${ }^{10}$ See, e.g., Gibbons (2011); Stringer and Barnes (2015).
} 
change our picture of the past, and has done so, frequently, in surprising ways. But often, the challenge for cognitive archaeological inference-making isn't having material to work with. After all, we have the many objects comprising the archaeological record and more objects are being unearthed and discovered. The challenge is having midrange theories which are sufficiently wellunderstood and constraining to reach into our cultural and cognitive histories—-to make sense of the cognitive within the remains. It is all very well to see the remnants of human sociality as information-rich, but if we lack ways of decoding that information, then cognitive archaeology likely cannot do better than the "entirely imaginative and unbridled exercises" (Renfrew 1993, p. 249) which Renfrew accuses post-processualist archaeologists of.

Why might the relevant midrange theory be so hard to come by? The problem is, in effect, the idiosyncratic and often arbitrary nature of cognition and culture. A major exception to our claim about general cognitive theories not playing much role in licencing inferences to the past is the recognition that human behaviour, culture and cognition is extremely plastic and contextsensitive. As lan Hodder puts it, "since all cognition is social, situated interpretations have to be made in any cognitive analysis" (Hodder 1993, p. 257). Midrange theories (like all theories!) rely upon repeated cases for evidential support (Tucker 1998), so if the relationship between cognition and remains is idiosyncratic, they might be empirically impoverished.

Modern (and, we think, attractive) models of human cognition both increase material engagement's importance but also the unique idiosyncrasy of those engagements. If humans are highly plastic, often using material objects to produce, in Lambros Malafouris' terms, "things that very often alter the ecology of our minds, re-configure the boundaries of our thinking and the ways we make sense of the world" (2015, p. 351), then those objects play critical roles in how our minds work — thus carrying rich, specific information—but unlocking their secrets becomes significantly trickier. If particular human cognitive expressions are unique in this sense our incapacity to overcome underdetermination of interpretation is not, as it were, our fault; it is not 
due to some methodological failing on our part (as Renfrew 1993 suggested), but rather due to the nature of the system at hand (Currie and Walsh 2018). To summarize: human material culture just is the remains of our idiosyncratic, context-specific cognition, so insofar as there is material culture, there are remains to work with. However, because of that idiosyncrasy, constructing and supporting middle-range theories linking remains to cognition is often difficult.

Having said this, there are reasons to doubt that the situation is discouragingly dire.

Minimal-capacity inferences often rely on well-grounded midrange theory. As we've seen, the production of ivory flutes requires impressive technical know-how, and a developed tradition is required to reach their levels of sophistication. Sometimes, then, cognition and its material remains are not so idiosyncratic. Further, when supported from multiple sources, causalassociation inferences can also have significant empirical grounding. Wynn (2017), for instance, places cognitive archaeology alongside paleoneurology (the study of patterns of brain morphology over evolutionary time), evolutionary psychology, and primatology (and we would add comparative psychology more generally). Moreover, we doubt we should bet against new midrange theories being developed in the future. Inferring from a lack of well-grounded theories now, to a lack in the future, bets against the ingenuity of future theorists (Currie 2015, 2018). Further, perfect analogues are not required to develop midrange theories: careful navigation between many different, imperfect evidential sources provides rich access to the past (Currie 2018 calls this 'exquisite corpse modelling').

Perhaps the problem lies in which midrange theories are in play. When cognitive archaeologists worry about their work's theoretical grounding they often have general theories in mind: representationalism versus enactivism, for instance. And yet, we've argued that empirically investigating the relationship between, say, working memory and the production of tools, or linguistic capacity and skill transferal, doesn't turn on such 'High Theorizing': cognitive 
archaeology succeeds with low-level, bottom-up midrange theory without dalliances with grand psychological theories.

The value of the archaeological record isn't exhausted by reconstructions of our cognitive past. Archaeologists are intimately concerned with things: tools, buildings, pottery. These are, after all, their primary evidence. As we saw in debates about the mental capacities required for constructing Acheulean tools, considering cognition from a thing-orientated perspective encourages the application of embodied, extended, distributed, and (more controversially) enactivist approaches to cognition in opposition to the computational approaches which predominate in cognitive science (Malafouris 2015; see also Renfrew 2008, pp. 119-120). Cognitive archaeology is ultimately about the relationship between human cognition and physical human artifice, and this perspective can challenge notions of cognition (Vallee-Tourangeau 2014; Kirsh 2014; Sterelny 2017).

Alison Wylie has long emphasized the capacity of the material record to upset deep-seated assumptions: over and again, objects have refused to play ball with our preconceptions (Wylie 2002, 2011; Chapman and Wylie 2016). Her 2002 book, which our title intentionally references, is Thinking from Things. In applying our conceptions of culture and cognition to the material record, we not only infer the cognitive from its downstream material effects: our thinking itself is challenged. As post-processualists emphasize, cognitive archaeology is necessarily a reflexive activity and, as such, in attempting to infer from things to thinking, we end up thinking from things. That is, our conception of cognitive possibility is challenged, developed and broadened. So, in addition to testing cognitive theories against the historical record, cognitive archaeology might itself be a source of those theories.

\section{Conclusion}


Cognitive archaeology is the practice of inferring from things to thinking, linking material remains to cognitive features of past humans and their societies via midrange theories. Inferences typically take the form of either minimal-capacity inferences (arguing that some cognitive capacity is a pre-condition for the production of some remain), or causal-association inferences (building an inductive association between a cognitive feature and remains, often using multiple evidence streams). Such practices inform us about the timing, nature, and trajectory of cognitive evolution. Insofar as theories about human uniqueness, language and so on turn on such properties, cognitive archaeology's importance reaches far outside of archaeology. We've argued the major challenge to cognitive archaeology is a lack of constraint from midrange theory, not impoverished material remains. However, we've also emphasized bottom-up midrange theories which do not require heavy psychological or neuroscientific theorizing. We've also emphasized that practice in cognitive archaeology is bidirectional: in attempting to infer from things to thinking, we find ourselves thinking about cognition and its relationship to things in new ways. Cognitive archaeology is not merely a line of evidence concerning past human lifeways; it is a source of new theories and perspectives about human life-ways and cognition.

\section{References}

Abramiuk, M. C. (2012) The Foundations of Cognitive Archaeology. Cambridge, MA and London: MIT Press.

Antón, S., Potts, R., \& Aiello, L. (2014). Evolution of early Homo: an integrated biological perspective. Science, 345(6192): 1236828.

Antón, S., \& Snodgrass, J. (2012). Origins and evolution of genus Homo: new perspectives. Current Anthropology, 53(supplement-6): s479-496.

Attwell, L., Kovarovic, K., \& Kendal, J. R. (2015). Fire in the Plio-Pleistocene: the functions of hominin fire use, and the mechanistic, developmental, and evolutionary consequences. Journal of Anthropological Sciences, 93: 1-20. 
Balter, M. (2015). World's oldest stone tools discovered in Kenya. Science, doi. 10.1126/science.aab2487

Barnard, P. J., Davidson, I., \& Byrne, R. (2017). Toward a richer theoretical scaffolding for interpreting archaeological evidence concerning cognitive evolution. In: T. Wynn \& F. Coolidge (eds), Cognitive models in Palaeolithic archaeology, pp. 45-68. Oxford University Press.

Bell, M. (2015). Experimental archaeology at the crossroads: a contribution to interpretation or evidence of 'xeroxing'? In R. Chapman \& A. Wylie (Eds.), Material Evidence, pp. 42-58. Routledge.

Bender, B. (1993). Cognitive archaeology \& cultural materialism. Cambridge Archaeological Journal, 3(2) 257-260.

Berwick, R. C., \& Chomsky, N. (2015). Why only us: language and evolution. MIT Press.

Binford, L. (1972). An archaeological perspective. New York: Seminar Press.

Bunn, H. T., \& Pickering, T. R. (2010a). Methodological recommendations for ungulate mortality analyses in paleoanthropology. Quaternary Research, 74(3): 388-394.

Bunn, H. T., \& Pickering, T. R. (2010b). Bovid mortality profiles in paleoecological context falsify hypotheses of endurance running-hunting and passive scavenging by early Pleistocene hominins. Quaternary Research, 74(3): 395-404.

Chapman, R., \& Wylie, A. (2016). Evidential reasoning in archaeology. Bloomsbury Publishing.

Chomsky, N. (2010). Some simple evo-devo theses: how true might they be for language? In: R. K. Larson, V. Déprez \& H. Yamakido (eds), The evolution of human language, pp. 45-62. Oxford University Press.

Chomsky, N. (2007). Biolinguistic explorations: design, development, evolution. International Journal of Philosophical Studies, 15: 1-21.

Conard, N., \& Malina, M. (2008). New evidence for the origins of music from the caves of the Swabian Jura. In: A. A. Both, R. Eichmann, E. Hickmann \& L.-Ch. Koch (eds), Challenges and objectives in music archaeology, pp. 13-22. Rahden: Verlag Marie Leidorf GmbH.

Conard, N., Malina, M., \& Münzel, S. (2009). New flutes document the earliest musical tradition in southwestern Germany. Nature, 460: 737-740.

Corballis, M. (2017). The truth about language: what it is and where it came from. Auckland University Press.

Currie, A., \& Killin, A. (2016) Musical pluralism and the science of music. European Journal for Philosophy of Science, 6(1), 9-30. 
Currie, A., \& Walsh, K. (2018). Newton on Islandworld: Ontic-driven explanations of scientific method. Perspectives on Science, 26(1), 119-156.

Currie, A. (2018). Rock, Bone, and Ruin: An Optimist's Guide to the Historical Sciences. MIT Press.

Currie, A. (2016). Ethnographic analogy, the comparative method, and archaeological special pleading. Studies in History and Philosophy of Science Part A, 55, 84-94.

Currie, A. (2015). Marsupial lions and methodological omnivory: function, success and reconstruction in paleobiology. Biology \& Philosophy, 30(2), 187-209.

Currie, G. (ms). Toolmaking and aesthetic culture in the Old Stone Age.

Darwin, C. (1871). The descent of man, and selection in relation to sex. Appleton \& Co.

Davidson, I., \& Noble, W. (1989). The archaeology of perception: traces of depiction and language. Current Anthropology, 30(2): 125-155.

D'Errico, F., et al. (2003). Archaeological evidence for the emergence of language, symbolism, and music —an interdisciplinary perspective. Journal of World Prehistory 17(1): 1-70.

Downes, S. M. (2010). The basic components of the human mind were not solidified during the Pleistocene epoch. In: Francisco J. Ayala \& Robert Arp (eds), Contemporary debates in philosophy of biology, pp. 243-252. Malden, MA: Wiley-Blackwell.

Fitch, W. T. (2010). The evolution of language. Cambridge University Press.

Flannery, K. V., \& Marcus, J. (1993). Cognitive archaeology. Cambridge Archaeological Journal, 3(2), 260-267.

Gibbons, A. (2011). Who were the Denisovans? Science 333(6046): 1084-1087.

Gibson, J. (1986). The ecological approach to visual perception. Lawrence Erlbaum, Hillsdale NJ.

Goren-Inbar, N., et al. (2004). Evidence of hominin control of fire at Gesher Benot Ya'aqov, Israel. Science, 304(5671): 725-727.

Gowlett, J. A. (2016). The discovery of fire by humans: a long and convoluted process. Philos Trans R Soc B, doi. 10.1098/rstb.2015.0164

Harmand, S., \& Lewis, J. E., et al. (2015) · 3.3-million-year-old stone tools from Lomekwi 3, West Turkana, Kenya. Nature, 521: 310-315.

Harris, O. J. (2018). More than representation: Multiscalar assemblages and the Deleuzian challenge to archaeology. History of the Human Sciences, 31(3): 83-104. 
Hawkes, C. (1954) Archeological Theory and Method: Some Suggestions from the Old World. American Anthropologist, 56: 155-168.

Hewes, G. W. (1973). Primate communication and the gestural origin of language. Current Anthropology, 14: 5-24.

Hiscock, P. (2014). Learning in lithic landscapes: a reconstruction of the hominid "toolmaking" niche. Biological Theory, 9(1): 27-41.

Hodder, I. (1993). Social Cognition. Cambridge Archaeological Journal, 3(2) 253-257.

Ion, A. (2017). How interdisciplinary is interdisciplinarity? Revisiting the impact of aDNA research for the archaeology of human remains. Current Swedish Archaeology, 25: 177-198.

Jeffares, B. (2010). The co-evolution of tools and minds: cognition and material culture in the hominin lineage. Phenomenology and the Cognitive Sciences, 9(4): 503-520.

Jeffares, B. (2008). Testing times: regularities in the historical sciences. Studies in History and Philosophy of Science part C, 39(4): 469-475.

Killin, A. (2018). The origins of music: evidence, theory, and prospects. Music \& Science, doi. $10.1177 / 2059204317751971$

Killin, A. (2017a). Plio-Pleistocene foundations of hominin musicality: coevolution of cognition, sociality, and music. Biological Theory, 12(4): 222-235.

Killin, A. (2017b). Where did language come from? Connecting sign, song, and speech in hominin evolution. Biology \& Philosophy, 32(6): 759-778.

Killin, A. (2016). Musicality and the evolution of mind, mimesis, and entrainment. Biology \& Philosophy, 31(3): 421-434.

Kirsh, D. (2014). The importance of chance and interactivity in creativity. Pragmatics \& Cognition, 22(1), 5-26.

Kosso, P (2001). Knowing the Past: Philosophical Issues of History and Archaeology. Humanity Books.

Kuhn, S. (2014). Signaling theory and technologies of communication in the Paleolithic. Biological Theory, 9(1): 42-50.

Lewontin, R. (1998). The evolution of cognition: questions we will never answer. In: Daniel Osherson, Don Scarborough \& Saul Sternberg (eds), Methods Models, and Conceptual Issues: An Invitation to Cognitive Science, Volume 4, pp. 107-132. Bradford, MIT Press.

Malafouris, L. (2015). Metaplasticity and the primacy of material engagement. Time and Mind, 8(4), 351-371. 
Marcus, J., \& Flannery, K. V. (1994). Ancient Zapotec ritual and religion: an application of the direct historical approach. In: Colin Renfrew \& Ezra Zubrow (eds), The Ancient Mind: Elements of Cognitive Archaeology, pp. 55-74. Cambridge University Press.

Marwick, B. (2003). Pleistocene exchange networks as evidence for the evolution of language. Cambridge Archaeological Journal, 13(1): 67-81.

Marzke, M. W. (2013). Tool making, hand morphology, and fossil humans. Philos Trans R Soc B, doi. 10.1098/rstb.2012.0414

McNabb, J., Binyon, D., Hazelwood, L. (2004). The large cutting tools from the South African Acheulean and the question of social traditions. Current Anthropology, 45(5): 653-677.

Mithen, S. (2005) The singing Neanderthals. Weidenfeld \& Nicolson.

Morley, I. (2013). The prehistory of music: human evolution, archaeology, and the origins of musicality. Oxford University Press.

Peebles, C. (1993). Aspects of cognitive archaeology. Cambridge Archaeological Journal, 3(2) 250-253.

Petraglia, M. D., Shipton, C., \& Paddayya, K. (2005). Life and mind in the Acheulean. In: C. Gamble \& M. Porr (eds), The individual hominid in context: archaeological investigations of Lower and Middle Palaeolithic landscapes, locales and artefacts, pp. 197-219. Routledge.

Petraglia, M. D., \& Shipton, C. (2008). Large cutting tool variation west and east of the Movius Line. Journal of Human Evolution, 55(6): 962-966.

Pickering, T. R., \& Bunn, H. T. (2012). Meat foraging by Pleistocene African hominins: tracking behavioral evolution beyond baseline inferences of early access to carcasses. In: M. DomínguezRodrigo (ed), Stone tools and fossil bones: debates in the archaeology of human origins, pp. 152173. Cambridge University Press.

Planer, R. J. (2017a). Protolanguage might have evolved before ostensive communication. Biological Theory, 12(2): 72-84.

Planer, R. J. (2017b). Talking about tools: did early Pleistocene hominins have a protolanguage? Biological Theory, 12(4): 211-221.

Planer, R. J. (2017c). How language couldn't have evolved: a critical examination of Berwick and Chomsky's theory of language evolution. Biology \& Philosophy, 32(6): 779-796.

Renfrew, C. (1993). Cognitive archaeology: some thoughts on the archaeology of thought. Cambridge Archaeological Journal, 3(2) 248-250.

Renfrew, C. (2008). Prehistory: the making of the human mind. London: Phoenix. 
Renfrew, C. (2012) Towards a cognitive archaeology: material engagement and the early development of society. In: I. Hodder (ed), Archaeological theory today, second edition, pp. 124145. Polity Press.

Ribeiro, A. (2018). Death of the passive subject: Intentional action and narrative explanation in archaeological studies. History of the human sciences, 31(3), 105-121.

Shipton, C., \& Nielsen, M., (2015). Before cumulative culture: the evolutionary origins of overimitation and shared intentionality. Human Nature, 26: 331-345.

Shipton, C. (2013). A million years of hominin sociality and cognition: Acheulean bifaces in the Hunsgi-Baichbal Valley, India. British Archaeological Reports International Series 2468. Archaeopress, Oxford.

Shipton, C., Petraglia, M. D., Paddayya, K. (2009). Inferring aspects of Acheulean sociality and cognition from lithic technology. In: B. Adams \& B. Blades (eds), Lithic materials and Palaeolithic societies, pp. 219-231. Wiley, Chichester.

Sterelny, K. (2017). Artifacts, symbols, thoughts. Biological Theory, 12: 236-247.

Sterelny, K. (2012). Language, gesture, skill: the co-evolutionary foundations of language. Philos Trans R Soc B, 367: 2141-2151.

Sterelny, K. (2003). Thought in a hostile world: the evolution of human cognition. Blackwell.

Stiner, M. C., \& Kuhn, S. L. (2016). Are we missing the "sweet spot" between optimality theory and niche construction theory in archaeology?. Journal of Anthropological Archaeology, $44,177-184$.

Stiner, M. C. (2013). An unshakable middle Paleolithic? Trends versus conservatism in the predatory niche and their social ramifications. Current Anthropology, 54(S8): S288-S304.

Stout, D. (2002). Skill and cognition in stone tool production: an ethnographic case study from Irian Jaya. Current Anthropology, 43(5): 693-722.

Stringer, C. B., \& Barnes, I. (2015). Deciphering the Denisovans. Proceedings of the National Academy of Sciences, 112(51): 15542-15543.

Tattersall, I. (2017). The material record and the antiquity of language. Neuroscience \& Biobehavioral Reviews, 81: 247-254.

Tomasello, M. (2008). Origins of human communication. MIT Press.

Tomlinson, G. (2015). A million years of music: the emergence of human modernity. Zone, New York.

Tucker, A. (1998). Unique events: the underdetermination of explanation. Erkenntnis, 48: 5980. 
Turner, D. (2005). Local underdetermination in historical science. Philosophy of Science, 72(1), 209-230.

Vallée-Tourangeau, F. (2014). Insight, interactivity and materiality. Pragmatics \& Cognition, $22(1), 27-44$.

Wrangham, R. (2009). Catching fire: how cooking made us human. Basic Books.

Wylie, Alison (2011). Critical distance: stabilising evidential claims in archaeology. In: Philip Dawid, William Twining \& Mimi Vasilaki (eds.), Evidence, Inference and Enquiry, pp. 371-394. Oxford University Press/British Academy.

Wylie, A. (2002). Thinking from things: Essays in the philosophy of archaeology. University of California Press.

Wylie, A. (1985). The reaction against analogy. In: Michael B. Schiffer (ed), Advances in Archaeological Method and Theory, Volume 8, pp. 63-111. Academic Press.

Wynn, T. (2017). Evolutionary Cognitive Archaeology. In: T. Wynn \& F. Coolidge (eds), Cognitive models in Palaeolithic archaeology, pp. 1-20. Oxford University Press. 